\title{
Mitochondrial "Hypermetabolic" Neurons in Paediatric Epileptic Foci
}

\author{
Harvey B. Sarnat, Laura Flores-Sarnat, Walter Hader, Luis Bello-Espinosa
}

\begin{abstract}
Background: Repetitively discharging neurons in epileptic foci have a high energy requirement that might be demonstrated histochemically as increased mitochondrial enzymatic activity in brain resections for epilepsy in children. Materials and Methods: Frozen sections were studied histochemically of 10 brain resections from 7 epileptic children, 2 months to 17 years of age. None had mitochondrial disease. Three patients had tuberous sclerosis (TS) or hemimegalencephy (HME). Tissues included hippocampus and neocortex. Oxidative enzymes were studied for respiratory chain complexes I, II, IV, using the muscle biopsy protocol. In addition, immunoreactivities of $\alpha$-B-crystallin and transmission electron microscopy (EM) were performed. Results: Oxidative activities were variable in adjacent neurons within a field: a minority were intense, adjacent to neurons with weaker mitochondrial activity exhibiting poor contrast of the soma because of similar oxidative activity in surrounding neuropil. Endothelium of vessels uniformly exhibits strong activity. Alpha-B-crystallin reactivity was strong at these foci. EM confirmed an abundance of neuronal mitochondria with normal cristae. In TS and HME, many dysplastic neurons showed intense activity; balloon cells had sparse activity. Conclusions: Histochemistry of mitochondrial oxidative enzymes reveals scattered and clustered neurons with stronger activities than others at epileptic foci. Such intensely staining neurons may be functionally "hypermetabolic" but they do not signify mitochondrial disease. Individual intensely stained neurons might be epileptogenic, but do not denote an epileptogenic field in the same manner as $\alpha$ B-crystallin, which also was strongly reactive in these foci.
\end{abstract}

RÉSUMÉ: L'histochimie des enzymes mitochondriaux montre des neurones hipermétaboliques dans les foyers épileptiques chez les enfants. Introduction: Les neurones quui déchargent répétément dans les foyers épileptiques requierent beaucop d'energie et se peut montrer à l'histochimie comme l'activité augmentée des enzymes oxidatifs mitochondriaux dans les resections du cerveau pour l'épilepsie chez les enfants. Matériels et Méthodes: On a étudié à l'immunohistochimie les sections congelées des 10 resections cerebrales chez 7 enfants de 2 mois a 17 ans d'âge, tous pour la epilepsie refractoire avec des foyers discrets. Aucun n'avaient pas de maladie mitochondriale. Trois patients avaient le sclérose tubéreuse (ST) ou l'hémimegalencéphlie (HME). Les tissus comprisent l'hippocampe et le cortex néo-cortical. Les enzymes mitochondriaux des complexes du châin respiratoire I, II et IV se sont examinés en utilizant le protocole des biopsies musculaires. Les immunoreactivités aux marqueurs neuronales, l' $\alpha$-Bcrystalline et aussi la microscopie éléctronique de transmission se sont realisés en tout les cas. Résultats: Les activités oxidatives étaient variable dans les neurones adjacentes dans un champ: une menorité étaient tres fortes, prêtes aux neurones d'activité mitochondrial plus faible et avec le manque de contraste entre le corps du neurone et le neuropile entouré. L'endothelie des vasseaux montre toujours l'activité oxidatif très fort. Le reactivité d' $\alpha$-Bcrystalline est fort dans ces foyers. La ME a confirmé l'abondance des mitochondries neuronales de crêtes normales. Les neurones dysplastiques chez les enfants aux ST et HME ont l'activité de grande intensité mais faible dans les cellules de ballon. Conclusions: L'histochimie des enzymes oxidatifs mitochondriaux montre des neurones qu'ont l'activité enzymatique plus fort que des autres dans les foyers épiléptiques. Ces neurones peut etre hypermétaboliques en function, mais ne signifiquent pas la maladie mitochondriale. Cette activité reconnait des neurones qui probablement sont épileptogéniques, mais ne défine pas un champ épileptique à la même façon que l'alpha-B-crystalline, bien qu'a confirmé un reactivité fort.

Can. J. Neurol. Sci. 2011; 38: 909-917

Repeatedly discharging neurons in epileptic foci have a high energy requirement derived from their mitochondria, and become "hypermetabolic". Increased mitochondrial activity might be demonstrated histochemically in individual neurons within foci identified as epileptogenic by preoperative electroencephalogram (EEG) and intraoperative electrocorticography $(\mathrm{ECoG})$ recordings. Three of the five Respiratory Chain Complexes (I, II, IV) can be histochemically defined; there are no reliable histochemical stains specific for Complexes III and V, however. The three Complexes for which reliable histochemical activities are shown have been routinely applied to muscle biopsies in most tertiary medical centres for more than three decades. These same techniques could be used to demonstrate mitochondrial oxidative activities in any tissue including brain, but have been employed only rarely in human brain resections or biopsies.

Reliable metabolic tissue markers of epileptic foci add a new dimension to the neuropathological examination of tissue resected for the treatment of intractable epilepsy in children and

From the Departments of Paediatrics [HBS, LFS, LBE], Pathology and Laboratory Medicine (Neuropathology)[HBS] and Clinical Neurosciences (Neurology) [HBS, LFS, LBE] and Neurosurgery) [WH], University of Calgary Faculty of Medicine and Alberta Children's Hospital, Calgary, Alberta, Canada.

Received April 15, 2011. Final Revisions Submitted May 30, 2011.

Correspondence to: H.B. Sarnat, Alberta Children's Hospital, 2888 Shaganappi Trail NW, Calgary, Alberta T3B 6A8, Canada. 
adults. They might help define whether the surgical excision of an epileptic focus was total or subtotal, analogous to the examination of tissue margins around a resected brain tumour to determine whether infiltrating neoplastic cells denote subtotal resection. For this purpose, a small heat-shock protein, $\alpha$-Bcrystallin, was recently described that fulfills the criteria of a tissue marker of epileptic foci ${ }^{1}$. The present study is an attempt to find other metabolic markers that can define an epileptic focus in hippocampal and neocortical tissues submitted during the course of epilepsy surgery in children.

The purpose of the present study was to examine mitochondrial respiratory chain enzymes in individual neurons by histochemistry, in frozen sections of freshly resected brain tissue, to attempt to distinguish hypermetabolic neurons in epileptic foci. The rationale was to test the hypothesis that epileptic foci alter the expression of oxidative enzymes and to compare results with biochemical analyses of brain homogenates of epileptic foci by other authors that indicate impaired mitochondrial function.

\section{Materials ANd Methods}

Between February 2009 and January 2011, we studied ten brain resections for epilepsy in eight children, five males and three females; three cases were repeat resections weeks to months after the first. Patients ranged in age from 2.5 months to
17 years. Electroencephalographically defined foci refractory to pharmacological control were confirmed and further defined by intra-operative ECoG. Magnetic resonance imaging (MRI) was performed preoperatively in all cases, using an epilepsy surgery protocol with finer than routine slices, but functional MRI, such as spectroscopy (MRS), SPECT and PET were not used because none of the patients were suspected of having a metabolic encephalopathy. No tumours were included in this study. None of the patients had clinical or neuropathological evidence of primary mitochondrial disease and none had progressive metabolic or neurodegenerative diseases.

The patients and their resections are summarized in the Table. One child had tuberous sclerosis (TS); two had hemimegalencephaly (HME), one of whom also had epidermal nevus syndrome; three had focal cortical dysplasias (ILAE type 1) of neocortex and mesial temporal sclerosis of the hippocampus; one child exhibited no histopathological lesions in neocortex but had hippocampal neuronal loss and gliosis. The number of male and female patients was equal. Most had developmental delay, attributed in part to poorly controlled epilepsy. All were taking multiple antiepileptic medications at the time of surgery and none were receiving the ketogenic diet.

Frozen sections of $4 \mu \mathrm{m}$ were prepared from the fresh tissue at the site of the neocortical epileptic focus as determined by intraoperative ECoG and $3 \mathrm{~cm}$ distal to this focus. Freezing was

Table: Brain resection cases studied

\begin{tabular}{|c|c|c|c|}
\hline Patient & Age/Gender & Site of Resection & Neuropathological Diagnosis \\
\hline 1 & $2 \mathrm{yr} / \mathrm{M}$ & $\mathrm{R}$ temporal tuber & tuberous sclerosis \\
\hline 2 & $2 \mathrm{mo} / \mathrm{M}$ & L temporal lobe & hemimegalencephaly \\
\hline $3 \mathrm{~A}$ & $7 \mathrm{mo} / \mathrm{M}$ & L temporal lobe & $\begin{array}{l}\text { hemimegalencephaly in } \\
\text { epidermal nevus syndrome }\end{array}$ \\
\hline $3 \mathrm{~B}$ & $14 \mathrm{mo} / \mathrm{M}$ & L inferior frontal lobe & $\begin{array}{l}\text { hemimegalencephaly in } \\
\text { epidermal nevus syndrome }\end{array}$ \\
\hline 4 & $17 \mathrm{yr} / \mathrm{F}$ & $\begin{array}{l}\mathrm{R} \text { temporal neocortex } \\
\mathrm{R} \text { hippocampus }\end{array}$ & $\begin{array}{l}\text { no microscopic lesions } \\
\text { mesial temporal sclerosis }\end{array}$ \\
\hline $5 \mathrm{~A}$ & $3 \mathrm{yr} / \mathrm{M}$ & $\begin{array}{l}\mathrm{L} \text { frontotemporal cortex } \\
\mathrm{L} \text { hippocampus }\end{array}$ & $\begin{array}{l}\text { focal cortical dysplasia } \\
\text { mesial temporal sclerosis }\end{array}$ \\
\hline $5 \mathrm{~B}$ & $5 \mathrm{yr} / \mathrm{M}$ & L inferior frontal cortex & focal cortical dysplasia \\
\hline 6 & $10 \mathrm{yr} / \mathrm{F}$ & $\begin{array}{l}\text { L temporal neocortex } \\
\text { L hippocampus }\end{array}$ & $\begin{array}{l}\text { focal cortical dysplasia } \\
\text { mesial temporal sclerosis }\end{array}$ \\
\hline 7 & $18 \mathrm{mo} / \mathrm{F}$ & $\begin{array}{l}\text { L lateral temporal cortex } \\
\text { L hippocampus }\end{array}$ & $\begin{array}{l}\text { focal cortical dysplasia } \\
\text { mesial temporal sclerosis }\end{array}$ \\
\hline 8 & $16 \mathrm{yr} / \mathrm{M}$ & $\begin{array}{l}\text { L temporal neocortex } \\
\text { L hippocampus }\end{array}$ & $\begin{array}{l}\text { mild focal cortical dysplasia } \\
\text { mesial temporal sclerosis }\end{array}$ \\
\hline
\end{tabular}

NOTE: The letters "A" and "B" after case number indicates two resections at different times of the same patient. $\mathrm{L}=\mathrm{left} ; \mathrm{R}=$ right; $\mathrm{M}=$ male; $\mathrm{F}=$ female; $\mathrm{mo}=$ months of age; yr=years of age 
performed in liquid nitrogen within five to ten minutes after resection. Hippocampal frozen sections taken from Ammon's horn generally included parts of the CA2 and CA 3 sectors. The dentate gyrus was included as well. In addition to staining with haematoxylin-eosin $(\mathrm{H} \& \mathrm{E})$ to exclude unsuspected neoplasms, histochemical stains were performed in the frozen sections using protocols routinely applied to muscle biopsies: 1) nicotinamide adenine dinucleotide-tetrazolium reductase (NADH-TR; respiratory complex I); 2) succinate dehydrogenase (SDH; respiratory complex II); 3) cytochrome-c-oxidase (COX; respiratory complex IV); 4) oil red $\mathrm{O}$ (neutral lipid stain); periodic acid-Schiff (PAS) reaction.

All tissues resected were examined microscopically and with multiple histochemical and immunocytochemical techniques applied to formalin-fixed, paraffin-embedded sections as markers of neurons, glial cells, inflammatory cells, as well as standard luxol fast blue for myelin, PAS for metabolic storage products and $\alpha$-B-crystallin. Antibodies against $\alpha$-B-crystallin (Covance: Emeryville, California, USA; polyclonal LAP-70 carboxy-terminus antibody against peptide of the last 14 amino acids; host: rabbit; 1:50 dilution incubated at $37^{\circ} \mathrm{C}$ ) were the same and the technique identical to those previously described ${ }^{1}$. The section facing and contiguous with the block taken for frozen sections was fixed in formalin without freezing, embedded in paraffin and $\alpha$-B-crystallin immuno-reactivity studied in $6 \mu \mathrm{m}$ sections. For acute and chronic gliosis, respectively, vimentin and polyclonal glial fibrillary acidic protein (GFAPp) were used. The vimentin antibody was used at 1:400 dilution, and GFAPp at 1:2000 dilution (both provided by DakoCytomatin, Denmark).

All tissues also were examined by transmission electron microscopy (EM) after fixation in $2.5 \%$ glutaraldehyde, postfixation in osmium tetroxide and staining with uranyl acetate and lead citrate. The small samples of tissue taken for EM were taken adjacent to the region from which the frozen sections were taken.

Controls are a difficult issue in this type of study. Mitochondrial enzymes rapidly degrade postmortem, hence brain tissue removed even within a couple of hours after death cannot serve as reliable controls for histochemical study. Citrate synthase can be measured in tissue homogenates as a function of number of mitochondria, but if only a few scattered neurons have proliferated mitochondria, they may be diluted to the point where they do not show a total increase in activity. Biopsies of normal brain are rarely available, especially in children. The normal cortex adjacent to tumours and other lesions, such as traumatic brain injuries, may not express normal mitochondrial activity, but might be the most practical and available option. We examined sections of cerebral cortex from two children, taken as margins adjacent to tumours (astrocytomas) that showed no infiltration by neoplastic cells or histological abnormalities.

\section{RESULTS}

General observations. In many regions of grey matter, particularly in the neocortex, oxidative enyzmatic activities showed poor contrast between neuronal somata and surrounding neuropil, not because there was no mitochondrial activity, but because the activity appeared relatively uniform due to a similar concentration of mitochondria in the perikaryon (soma) of the neuron and its neurites that comprised much of the neuropil. However, scattered hypermetabolic neurons were easily identified by their intense reactivity, providing strong contrast with the background neuropil. Activity was usually, but not always, stronger with $\mathrm{NADH}$ than with $\mathrm{SDH}$ and was least intense with COX.

Oil red O stain did not show excessive neutral lipid in any of the brain tissues or in individual neurons in any of the cases. PAS did not disclose excessive glycogen or loss of glycogen from neurons, and revealed no metabolic storage material.

Alpha-B-crystallin showed strong immunoreactivity in glial cells and some neurons in the grey matter and especially the underlying white matter at epileptic foci in tissue contiguous with the frozen block and included the same cortical grey and subcortical white matter. Some of the patients in this study were previously described in relation to $\alpha$-B-crystallin in a previous paper $^{1}$.

Tuberous sclerosis. Nearly all of the dysplastic and cytomegalic neurons in the cortical tuber and in subcortical white matter heterotopia exhibited intense cytoplasmic mitochondrial activity with all three enzymes (Figure 1). Balloon cells, by contrast, showed very weak to no reactivity or reactivity was confined to a thin rim at the margin of the soma, particularly well demonstrated by SDH and less with NADH and COX (Figure 1).

Hemimegalencephaly. Both cases were similar. Dysplastic cells in the cortical grey matter were intensely reactive (Figure 2), similar to the cytomegalic neurons in tuberous sclerosis but fewer in number. Most neurons showed reactivity that was moderate and differed little from the surrounding neuropil, thus providing poor contrast for distinction of the soma. Balloon cells were not included in these sections.

Hippocampi in non-TS and non-HME cases. CA2 and CA3 sectors were identified by activity for each of the three respiratory chain enzymes in their cytoplasm, but only about $10 \%$ of total neurons contrasted strongly with surrounding neuropil by intense punctate activity in the cytoplasm of the soma and proximal dendritic trunk and axonal hillock. Remaining neurons were more difficult to visualize because the surrounding neuropil exhibited punctate mitochondrial activity in neurites that was similar to that of the somatic cytoplasm. (Figures 3B,C). Scattered degenerating neurons showed loss of mitochondrial activity and the presence of these necrotic cells was confirmed by EM. NADH-TR showed stronger activity in the same neurons than did SDH or COX. Granule cells of the dentate gyrus were uniformly more weakly reactive with all three oxidative enzymes examined than the larger pyramidal neurons of Ammon's horn (Figure 3A), perhaps in part because of sparser cytoplasmic volume. Most large neurons adjacent to either the dentate gyrus or to Ammon's horn were strongly reactive. The intensity of reactivity in the pyramidal and other large neurons was not related to the volume of the cytoplasm, however, because neurons of equal size showed either intense activity or more moderate activity similar to surrounding neuropil. In places, intensely active pyramidal cells were loosely grouped within Ammon's horn (Figure 3C), and in other regions they were more isolated and single and contrasted sharply with surrounding neuropil within a field of only moderately active neurons with poor somatic demarcation from neuropil. 


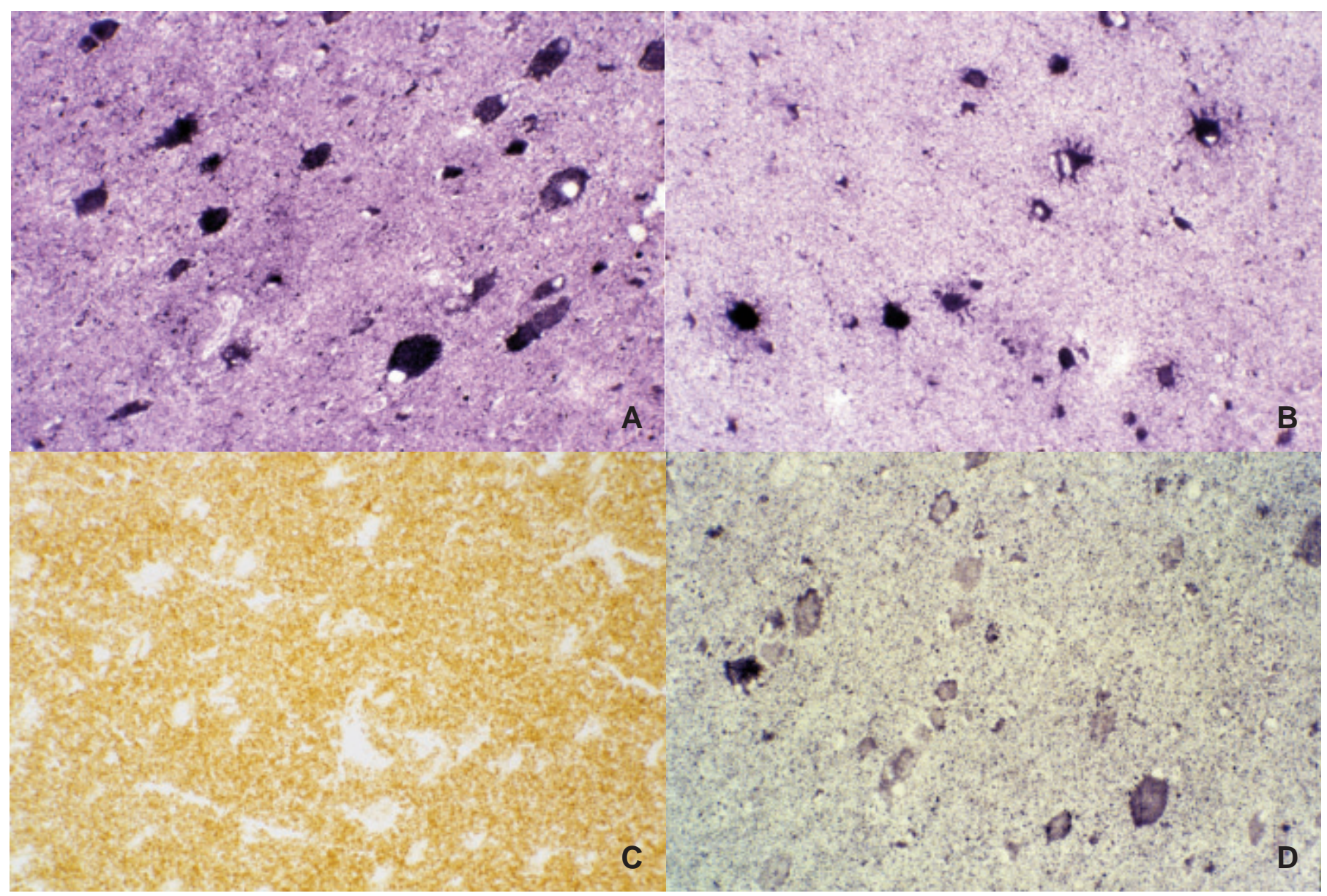

Figure 1: Case 1: 2-year-old boy with tuberous sclerosis undergoing resection of a highly epileptogenic cortical tuber. (A) NADH-TR and (B) SDH activities show intense reaction of dysplastic neurons, both megalocytic forms and those of normal size. (C) COX activity is more uniform amongst neurons and shows only scattered regions of intense activity; most neurons show little contrast with background neuropil because the concentration of mitochondria is similar; balloon cells, glial cells and processes appear white because of lack of COX expression. (D) In the white matter beneath the cortical tuber, SDH activity also is strong in dysplastic neurons, but balloon cells and atypical astrocytes show activity mainly confined to the margin of the cytoplasm, not in the central region. X250. Also see Figure 7.

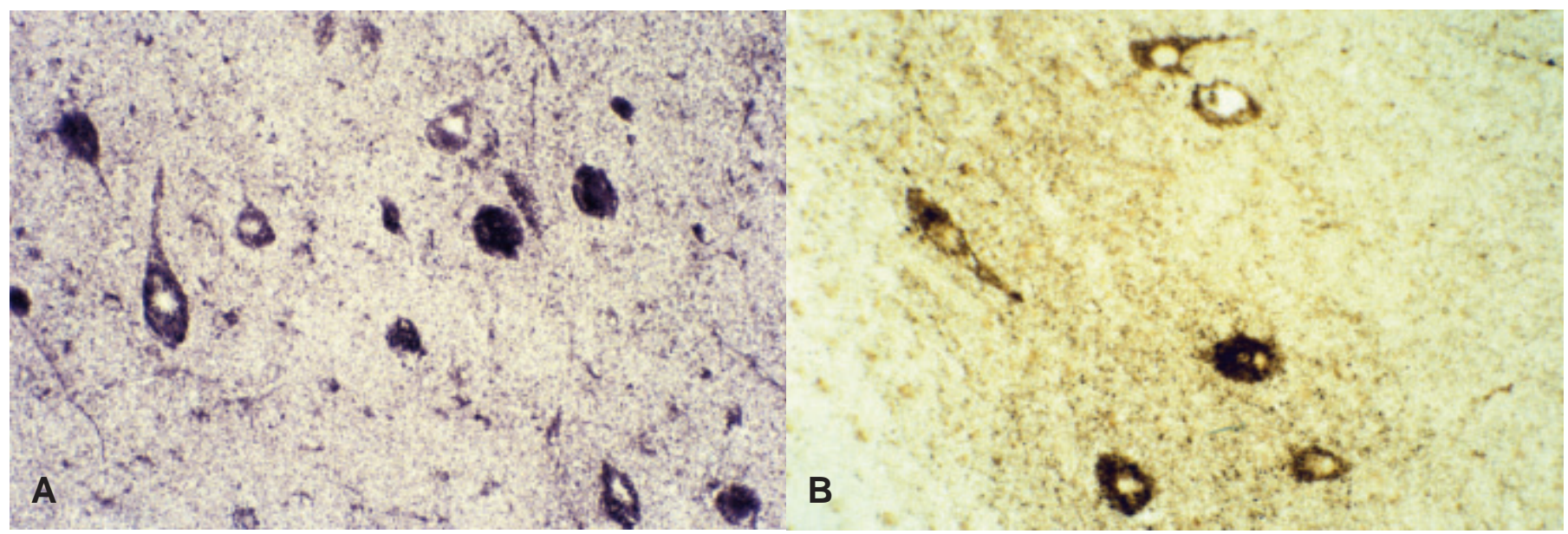

Figure 2: Case 2. 21/2-month-old boy with left hemimegalencephaly and intractable epilepsy. (A) NADH-TR and (B) COX activities show many scattered dysplastic neurons that appear hypermetabolic because of their intense staining. Another patient with hemimegalencephaly and epidermal nevus syndrome, a 7-month-old boy and a second resection at age 14 months, was similar but fewer neurons were intensely stained (not shown). X250. 
Acute gliosis in the hippocampal sections and/or chronic gliosis, indicated by vimentin and polyclonal GFAP, respectively, and the demonstration of neuronal loss and degeneration, confirmed by ultrastructural examination, are features defining "mesial temporal sclerosis". They were present to a variable degree in all of the hippocampi included in this study.

Neocortex in non-TS and non-HME cases. Temporal and frontal neocortex showed strong reactivity, similar to that described above in the hippocampus, but nonuniformly and only about $20 \%$ of total large pyramidal neurons, mainly in deep layers, showed activity (Figures 3-5), weaker activity was observed in most of the other layers and also in the smaller granule cells in layers 2 and 4 . No differences were detected between sections taken at the site of the epileptic focus and those taken distal to it. Degenerating neurons, confirmed by EM, exhibited loss of activity.

Comparison with $\alpha$-B-crystallin reactivity in adjacent formalin-fixed, paraffin-embedded sections showed intense upregulation of this protein in glial cells within the epileptogenic region studied with oxidative enzymes. No inflammatory cell infiltrates, microglial activation or vascular lesions were demonstrated in the cases here studied.

Endothelium. Endothelial cells normally contain many mitochondria and extensive granular endoplasmic reticulum in their cytoplasm. Histochemically, endothelial cells always are intensely stained for all three oxidative enzymatic activities used in this study. This phenomenon is routinely seen in muscle biopsies and also is seen in other tissues including intracerebral and meningeal capillaries, as noted in this present study (Figure 6). Strong reactivity thus has no pathological implications, but does provide an additional internal control against which to compare neuronal activity in the same section. No differences were demonstrated in endothelial oxidative activity between cases of various ages or between the TS and HME cases and those with no underlying systemic disorders.

Control tissues. The sections at the noninfiltrated margins of tumours showed nearly uniform enzymatic activities in the cortex with poor distinction of neuronal somata because the surrounding neuropil was equally strong. Individual neurons did not contrast by intense activity in the same manner as those shown in epileptic foci in this study.

Transmission electron microscopy. Many, but not all, neocortical and hippocampal neurons demonstrated abundant and excessive mitochondria, compared with others in the same region of the same grid. These neurons with hyperplasia of mitochondria probably corresponded to the neurons with intense oxidative activity by histochemistry. Mitochondria had well formed cristae without stacking or whorling and no paracrystallin structures were demonstrated. Osmophilic spheroids were sparse within the mitochondrial matrix. Other organelles, including granular endoplasmic reticulum, also were well preserved. There was excessive satellitosis, however, as is frequent in epileptic foci in cerebral cortex. Glial cells had normal ultrastructural morphology and mitochondria of astrocytes and oligodendrocytes, including satellite cells, were

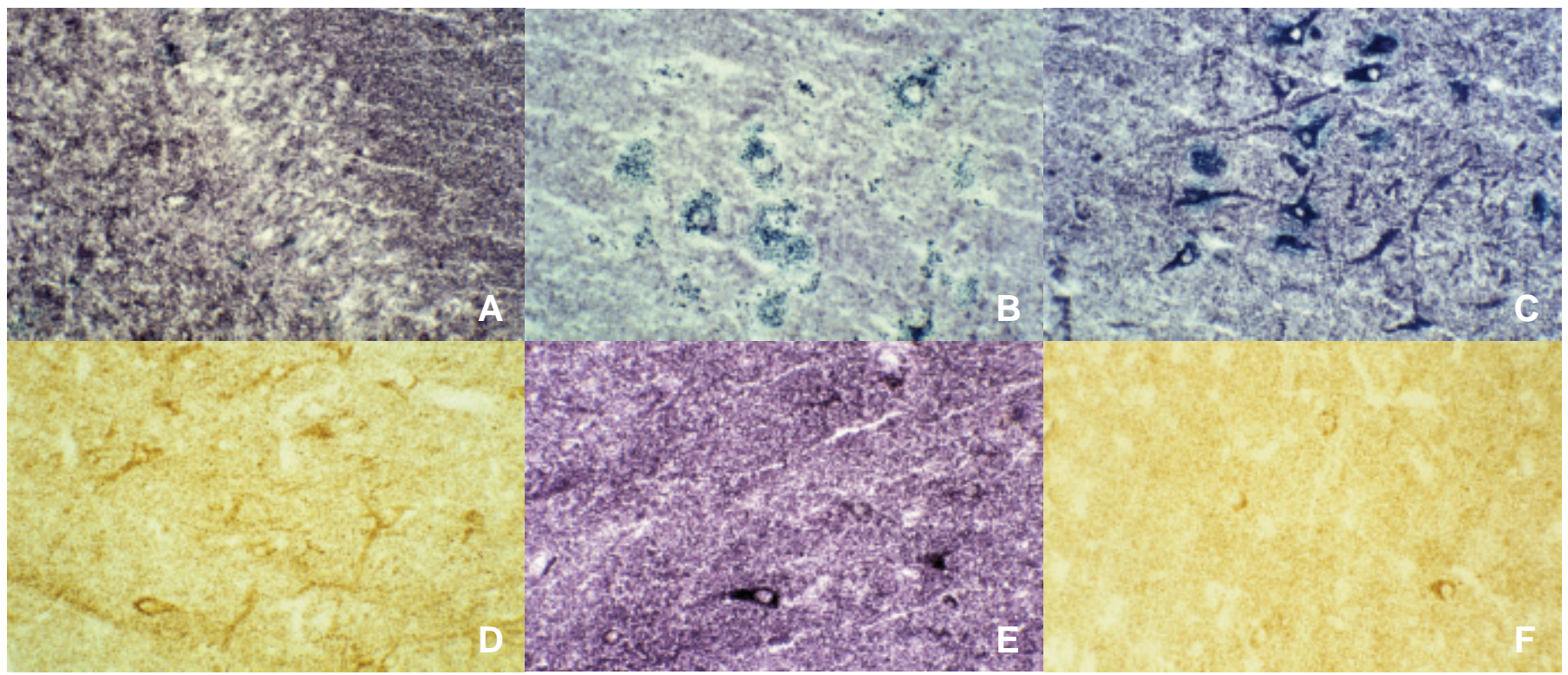

Figure 3: Case 4. 17-year-old girl with refractory partial epilepsy and resection of EEG focus in R temporal and inferior frontal lobes. (A) The dentate gyrus shows strong NADH-TR activity in the thin cytoplasmic rim of granular neurons and especially in the molecular zone within the mossy fibres (upper left); intense activity also is seen in the larger neurons adjacent to the dentate gyrus (lower right). (B) NADH-TR activity also is strong in pyramidal neurons, including their long neurites, of the CA3 sector of Ammon's horn. (C) SDH and (D) COX activities in Ammon's horn also are strong. Hypermetabolic neurons tend to cluster in places. (E) Neocortex contains many scattered neurons, intensely stained with NADH-TR, amongst others that are less active and blend with the surrounding neuropil. $(F)$ COX activity is strong in fewer neurons that was seen with NADH-TR. SDH activity (not shown) was similar to NADH-TR.X250. 


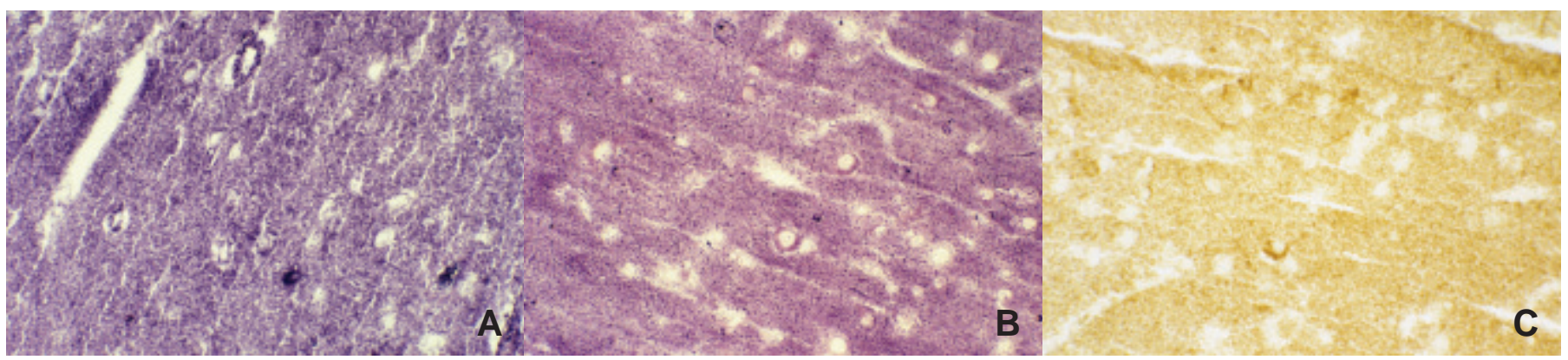

Figure 4: Case 5B. 5-year-old girl with epileptic focus associated with focal cortical dysplasia in inferior frontal lobe. (A) NADH-TR, (B) SDH and (C) $C O X$ activities are strong in scattered neurons only and most of the background activity is uniform because of poor contrast between neuronal somata and surrounding neuropil, similar to controls. A parenchymal capillary shows strong activity in its endothelium. X250.

neither excessive in number nor abnormal in ultrastructure. Figure 7 shows two neurons from the cortical tuber illustrated in Figure 1. An abundance of cytoplasmic mitochondria with well formed cristae is evident.

\section{DISCUSSION}

Epilepsy is a frequent neurological manifestation in children and adults with mitochondrial encephalopathies associated with respiratory chain deficiencies ${ }^{2-13}$. Studies of mitochondrial function in epilepsy in patients without primary mitochondrial disease also generally show impaired activity, alteration of the link between mitochondrial function, oxidative stress, redox status and mitochondria-dependent apoptotic neuronal signaling precipitated by seizures. Since mitochondrial oxidative phosphorylation provides the major source of adenosine triphosphate (ATP) synthesis in neurons and mitochondria participate in calcium homeostasis, mitochondrial dysfunction can strongly affect neuronal excitability and synaptic transmission ${ }^{10}$ and impairment of redox status ${ }^{14}$. Histochemical determination of optic density in piriform cortex after pilocarpine-induced status epilepticus in adult rats shows nonuniform distribution of COX-reactive neurons ${ }^{15}$, similar to the results we here report in human resections of active epileptic foci. Though all of the mechanisms are not yet fully defined, it is becoming increasingly evident that mitochondria play a major role in epileptogenesis. To indicate mitochondrial hyperplasia in individual neurons that results in hyperintense histochemical enzymatic activity, we have employed the term "hypermetabolic" because it summarizes the concept in a single word, recognizing that the term is new in this context and is somewhat presumptive by its implication of function.

Homogenates of tissue samples of brain for biochemical determinations and in vitro brain slice preparations cannot recognize scattered individual neurons with increased histochemical enzymatic activity or "hypermetabolism", the latter a speculative extrapolation to function. Histochemistry
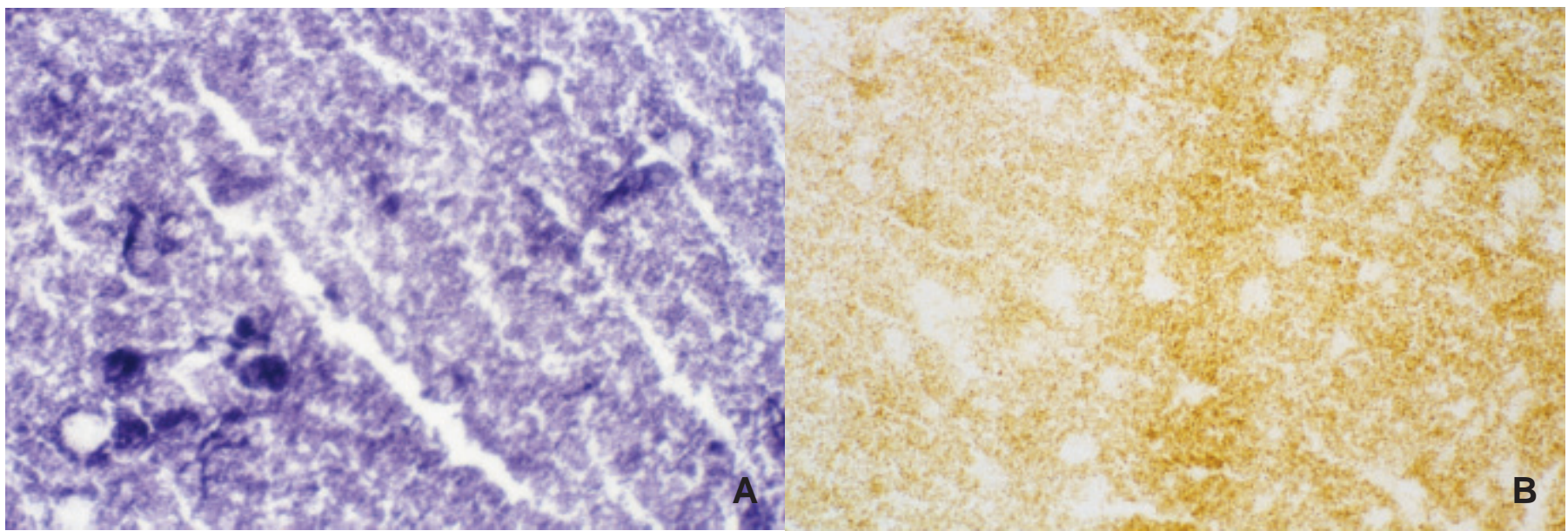

Figure 5: Case 6. 10-year-old boy with lateral temporal neocortical epileptic focus and focal cortical dysplasia. The hippocampus showed mesial temporal sclerosis. (A) NADH-TR activity in the temporal neocortex is strong in clustered and scattered neurons, but most neurons show only the expected moderate activity. (B) COX activity is not as intense as with NADH-TR or SDH (not shown), but individual neuronal somata are still identified because of more intense punctate mitochondrial activity than in surrounding neuropil. X250. 
thus enables a different and contrasting perspective to biochemical evidence and explains the generally accepted view that mitochondrial activity is defective at epileptic foci based on quantitative assay of tissue homogenates. Despite increasingly strong interest in the surgical treatment of refractory epileptic foci, there are few previous studies using histochemical techniques to demonstrate specific activity in three of the five mitochondrial respiratory chain complexes which can be demonstrated by this method. These three enzymes, routinely used for muscle biopsies, are rarely applied to brain resections. Histochemistry is always a semi-quantitative technique and comparisons of stain intensity and localization are the bases. Comparisons between different enzymatic stains is not as reliable as comparing the same enzyme between cases or comparing different neurons within the same section, which is the most convincing. Epileptic foci are localized preoperatively and intraoperatively by electophysiological recording and structural lesions often are identified preoperatively by neuroimaging. The neuropathologist has a parallel need for tissue markers of epileptic foci when examining resected tissue. Neuropathological examination of epileptic foci includes not only the diagnosis of structural lesions, such as focal cortical dysplasias and tumours, but also detection of epileptogenic tissue at the margins of the resection by metabolic markers. Alpha-Bcrystallin is such a marker, defining a relatively wide field of an epileptic focus ${ }^{1}$. The correlation of this heat-shock protein and mitochondrial enzyme activity in individual neurons with EEG and ECoG recordings can provide unique validation of electrophysiological techniques in defining an epileptic focus.

The histochemical demonstration of mitochondrial respiratory chain enzymes in brain tissue is neither recent nor novel. The three enzymes employed in our present study, NADH-TR, SDH and COX, were described in human brain in Emson's classical 1983 textbook of histochemistry of the human

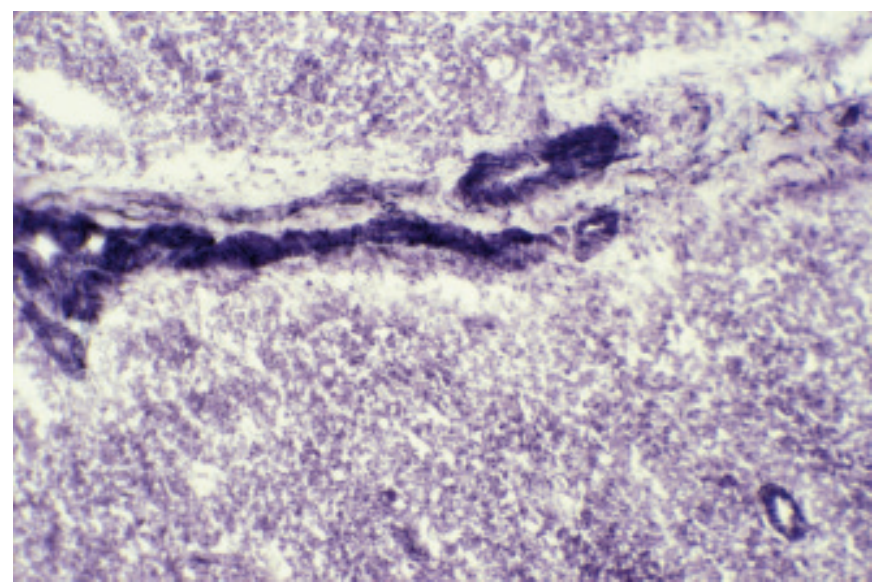

Figure 6: Case 7. 18-month-old girl with L lateral temporal epileptic focus and focal cortical dysplasia. NADH-TR activity is strong in a few scattered neurons. Meningeal arterioles in a sulcus between two gyri exhibit intense mitochondrial activity in their endothelia; a parenchymal capillary also is intensely stained. X100.

brain, in chapters by Graybiel et al. on the corpus striatum ${ }^{16}$ and Jones on the thalamus ${ }^{17}$. These same histochemical methods, fundamentally the same as the ones we now use, had been applied even earlier, by Manocha and Shantha in 1970, in their treatise of histochemical mapping of the monkey brain ${ }^{18}$. An even earlier study by Friede in 1959 examined the immature rat brain $^{19}$. Most of these early studies were more focused on brainstem and subcortical structures than on the cerebral cortex, and the results in both were inconclusive because of uniformity of activity between neurons and neuropil without neuronal

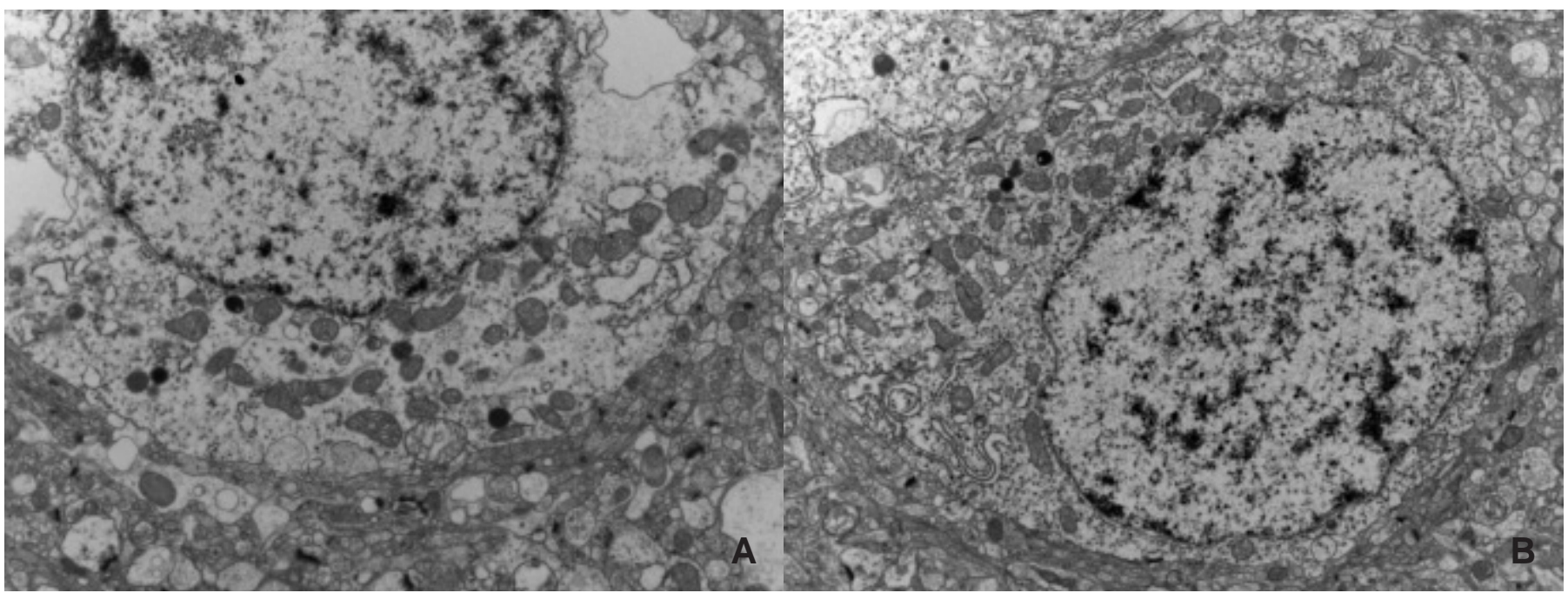

Figure 7: Case 1. Electron micrographs of two dysplastic neurons within a cortical tuber. The number of mitochondria is greater than seen in most neurons and appears to correlate with the increased oxidative activity shown in Figure 1. These abundant mitochondria each have normal cristae and none exhibit the expected ultrastructural features diagnostic of primary mitochondrial cytopathies. Osmium tetroxide, uranyl acetate and lead citrate. (A) $X 120,000 ;$; (B) X90,000. 
somata being easily distinguished from the background activity, except for regional differences in intensity. This pattern is similar to our controls and to many regions of the cortex in focal dysplasias, as exemplified in our Figure 4. In contemporary neuropathology practice, the histochemical demonstration of mitochondrial oxidative enzymes is largely limited to muscle biopsies. The number of mitochondria, and particularly subsarcolemmal clustering in myofibres, correlates with the intensity of histochemical staining of oxidative enzymes and with the biochemical assay of respiratory chain complexes ${ }^{20}$; this same principle probably is as true in neurons as in myocytes.

As with muscle, one disadvantage of these stains in brain is that they require freshly frozen sections and cannot be applied to formalin-fixed, paraffin-embedded sections. But frozen H\&Estained sections often are performed intraoperatively to determine the presence of a neoplasm. Mitochondrial enzymes are performed in frozen sections of intestinal biopsies of infants to denote the maturity of ganglion cells ${ }^{21}$.

Mitochondrial oxidative enzymes demonstrated histochemically thus provide a marker of individual "hypermetabolic" neurons within an epileptic focus, but are not a marker of a wide field of epileptogenic cerebral tissue in the same manner as $\alpha$-B-crystallin, though immunoreactivity of the latter was strong at these foci. One can speculate that these intensely stained cells are actively discharging neurons intrinsic to the epileptic focus and hyperplasia of normal mitochondria is a response to increased energy requirements. The NADH activity often was stronger than SDH or COX, probably in part because $\mathrm{NADH}$ (Complex I) is expressed in endoplasmic reticulum as well as in mitochondria, whereas SDH (Complex II) and COX (Complex IV) are pure mitochondrial enzymes. Endothelial cells of capillaries and arterioles also exhibited uniform strong oxidative activity, as they always do in normal muscle biopsies, brain and other tissues. In mitochondrial cytopathies of infancy and early childhood, endothelial mitochondria are ultrastructurally altered earlier and more severely than those of myofibres ${ }^{22}$, and presumably they also are altered early in the brain, contributing to lesions such as those of Leigh encephalopathy ${ }^{7}$. Whether endothelial mitochondrial activity increases neuronal mitochondrial enzymes is poorly documented. Another uncertain factor that may influence the overexpression of mitochondrial activity in some neurons in epilepsy is the phenomenon of satellitosis, i.e. the adherence of glial cells to neuronal somata, which displaces inhibitory axosomatic synapses without affecting the mainly excitatory axodendritic synapses; satellite glia also may transfer excessive glutamine into neurons to which they adhere for increased intraneuronal glutamate synthesis ${ }^{23}$. Satellite glial cells in cortical grey matter at epileptic foci often are intensely reactive for $\alpha$-B-crystallin ${ }^{1}$.

The reason that all neurons in a region of Ammon's horn or neocortex are not uniform in their expression of oxidative enzymatic activities is not a factor of neuronal size or cytoplasmic volume, nor is it due to degenerative or necrotic changes in some neurons in which loss of mitochondrial activity would be expected. The proportion of weakly reactive neurons with oxidative enzymes greatly exceeds the number of degenerating or necrotic neurons demonstrated by EM. Lack of uniformity of expression of enyzmes between adjacent neurons is neither a technical artifact nor due to delay in prompt freezing of tissue after resection.

Another factor that may influence mitochondrial activity in epilepsy, in general by impeding it, is antiepileptic drugs $s^{7,24,25}$ and the ketogenic $\operatorname{diet}^{26}$. It is even suggested that differences in mitochondrial function may be a basis for refractoriness of pharmacological control of seizures in some patients and not in other $^{27}$. All of our patients in this study were taking multiple antiepileptic medications preoperatively, though none was using ketogenic dietary therapy.

In tuberous sclerosis there may be unique factors causing increased mitochondria and augmenting oxidative activity because neurons lacking the TSC1/TSC2 protein complex have increased vulnerability to endoplasmic reticulum stress-induced cellular death via a mechanism that involves the mTOR pathway ${ }^{28}$; increased mitochondrial activity in such neurons that we here demonstrate may be an attempted compensatory response. Compensatory hypermetabolism with increased mitochondrial activity in individual neurons may occur for other reasons in epilepsy in children who do not have tuberous sclerosis.

The queries posed in this study cannot be fully resolved because of the difficult issue of reliable control human brain tissue of matched age and unreliability of tissue taken for this purpose postmortem. Animal studies may be able to document whether the "hypermetabolic" neurons with increased mitochondrial oxidative activity are indeed actively discharging epileptogenic neurons, as well as provide suitable controls of histochemically demonstrated enzymatic activity in normal cerebral cortex and hippocampus. We are pursuing another approach of quantitative measurement of mitochondrial activity in blocks of tissue from epileptic foci, including comparisons of each of the five respiratory chain complexes individually and the measurement of citrate synthase as an indicator of total mitochondrial volume. This type of study involves tissue homogenates and does not identify individual neurons in the same manner as the present histochemical study, hence is complimentary to histochemistry but is not an alternative providing greater precision. Indeed the hypermetabolism of an individual neuron may be so diluted in tissue homogenates that it cannot be recognized by biochemical assay.

\section{Conclusions}

Histochemical demonstration of increased mitochondrial respiratory chain enzymes in scattered individual neurons at epileptic foci suggests hyperplasia of normal mitochondrial in those cells, corroborated by ultrastructure. This histochemical finding may be an indicator of increased metabolism. Whether it also identifies individual repetitively discharging neurons that generate electrophysiological spikes and clinical seizures, remains speculative at this time, but is an hypothesis that merits further study. Increased mitochondrial enzymatic activity in individual neurons is another metabolic marker at an epileptic focus, but does not demarcate such foci as a wide field in the same manner as does $\alpha$-B-crystallin. 


\section{ACKNOWLEDGEMENT}

Three of the patients were initially under the neurological care of Dr. Ismail Mohamed, who also interpreted their EEG recordings. We thank the technical staff of the Calgary Laboratory Services at Alberta Children's Hospital (Gaston Guenette and Patricia McGinnis), of the Neuropathology Laboratory at Foothills Regional Provincial Hospital (Vivian King and her staff), and the Electron Microscopy Laboratory (Elaine Yung and Weyman Chan) for the meticulous quality of tissue preparations and pride they take in their work.

\section{Disclosure}

This work was supported in part by the Dept. of Pathology and Laboratory Medicine, University of Calgary and in part from a grant from the Kinsman Chair in Paediatric Neurosciences Research.

\section{REFERENCES}

1. Sarnat HB, Flores-Sarnat L. $\alpha$-B-crystallin as a tissue marker of epileptic foci in paediatric resections. Can J Neurol Sci. 2009;36: 566-74.

2. Bertrand E, Fidziańska A, Schmidt-Sidor B, Mendel T. Mitochondrial encephalomyopathy of mixed MELAS type. Folia Neuropathol. 1996;324:193-8.

3. Canafoglia L, Franceschetti S, Antozzi C, et al. Epileptic phenotypes associated with mitochondrial disorders. Neurology. 2001;56:1340-6.

4. Kunz WS. The role of mitochondria in epileptogenesis. Curr Opin Neurol. 2002;15:179-84.

5. Patel M. Mitochondrial dysfunction and oxidative stress: cause and consequence of epileptic seizures. Free Radical Biol Med. 2004; 37:1951-62.

6. Kann O, Kovács R. Mitochondria and neuronal activity. Am J Physiol Cell Physiol. 2007;292:C641-57.

7. Cock H. The role of mitochondria in status epilepticus. Epilepsia. 2007;48 Suppl 8:24-7. Erratum in: Epilepsia 2007;48:2382.

8. Khurana DS, Salganicoff L, Melvin JJ, et al. Epilepsy and respiratory chain defects in children with mitochondrial encephalopathies. Neuropediatrics. 2008;39:8-13.

9. Milinari F, Kaminska A, Fiermonte G, et al. Mutations in the mitochondrial glutamate carrier SLC25A22 in neonatal epileptic encephalopathy with suppression bursts. Clin Genet. 2009;76: $188-94$.

10. Kudin AP, Zsurka G, Elger CE, Kunz WS. Mitochondrial involvement in temporal lobe epilepsy. Exp Neurol. 2009;218: 326-32.

11. Chuang YC. Mitochondrial dysfunction and oxidative stress in seizure-induced neuronal cell death. Acta Neurol Taiwan. 2010; 19:3-15.

12. Waldbaum S, Patel M. Mitochondria, oxidative stress and temporal lobe epilepsy. Epil Res. 2010:88:23-45.
13. Chen SD, Chang AY, Chuang YC. The potential role of mitochondrial dysfunction in seizure-associated cell death in the hippocampus and epileptogenesis. J Bioenerg Biomembr. 2010; 42:461-5

14. Waldbaum S, Liang LP, Patel M. Persistent impairment of mitochondrial and tissue redox status during lithiumpilocarpine-induced epileptogenesis. J Neurochem. 2010;115: 1172-82.

15. Otáhal J, Suchomelová L, Druga R, Kubová H. Changes in cytochrome oxidase in the piriform cortex after status epilepticus in adult rats. Epilepsia. 2005;46 Suppl 5:89-93.

16. Graybiel AM, Ragsdale CW Jr. Biochemical anatomy of the striatum. In: Emson PC, editor. Chemical neuroanatomy. New York: Raven Press; 1983. p. 445-8.

17. Jones EG. The thalamus. In: Emson PC, editor. Chemical neuroanatomy. New York: Raven Press; 1983. p. 283-4.

18. Manocha SL, Shantha TR. Macaca mulatta: Enzyme histochemistry of the nervous system. New York, London: Academic Press; 1970. p. 15, 122, 185.

19. Friede RL. Histochemical investigations on succinic dehydrogenase in the central nervous system. I. Distribution in the developing rat's brain. J Neurochem. 1959;4:101-11.

20. Miles L, Miles MV, Horn PS, DeGrauw AJ, Wong BL, Bove KE. Decreased mitochondrial subsarcolemmal aggregates are associated with respiratory chain deficiency in muscle of pediatric patients. Mitochondrion. In press 2011.

21. Feichter S, Meier-Ruge WA, Bruder E. The histopathology of gastrointestinal motility disorders in children. Sem Pediatr Surg. 2009;18:206-11.

22. Sarnat HB, Khan A, Flores-Sarnat L, Casey R, Scott P. Endothelial ultrastructural alterations of intramuscular capillaries in infantile mitochondrial cytopathies. 2011; submitted.

23. Sarnat HB, Flores-Sarnat L, Hader W. Satellite glia in epilepsy: guardian angels or assassins of neurons? Proceedings of the XII International Congress of Neuropathology. Rome: Medimond. 2010. p. 83-91.

24. Silva MFB, Aires CCP, Luis PMB, et al. Valproic acid metabolism and its effects on mitochondrial fatty acid oxidation: a review. J Inherit Metab Dis. 2008:31:205-16.

25. Berger I, Segal I, Shmueli D, Saada A. The effect of antiepileptic drugs on mitochondrial activity: a pilot study. J Child Neurol. 2010;25:541-5.

26. Balietti M, Giogetti B, Di Stefano G, et al. A ketogenic diet increases succinic acid dehydrogenase (SDH) activity and recovers age-related decrease in numeric density of SDHpositive mitochondria in cerebellar Purkinje cells of late-adult rats. Micron. 2010;41:143-8.

27. Jiang W, Du B, Chi Z, et al. Preliminary explorations of the role of mitochondrial proteins in refractory epilepsy: some findings from comparative proteomics. J Neurosci Res. 2007;85:3160-70.

28. Di Nardo A, Kramvis I, Cho N, et al. Tuberous sclerosis complex activity is required to control neuronal stress responses in an mTOR-dependent manner. J Neurosci. 2009;29:5926-37. 